\title{
BODY FAT COMPARISON BETWEEN BASKETBALL AND NETBALL PLAYERS IN MALAYSIA
}

\author{
Soh $K G^{\prime}$, Ruby $H^{2}$ and Soh $K L^{3}$ \\ Sports Studies Department, Faculty of Educational Studies, University Putra Malaysia, 43400 UPM Serdang, Selangor Darul Ehsan, Malaysia \\ 2 Physiology Department, Medical Faculty, University of Malaya, 50603 Kuala Lumpur, Malaysia. \\ ${ }^{3}$ Department of Community Health, Faculty of Medicine and Health Sciences, University Putra Malaysia, Kuala Lumpur, Malaysia
}

\begin{abstract}
The aim of the study was to compare the body fat percentages between Malaysian national women basketball players and netball players. Both basketball and netball players were elite players who represented Malaysia in the 1997 Southeast Asia Games in Jakarta, Indonesia and the 1998 Commonwealth Games in Kuala Lumpur. The percentage of body fat was determined by means of skinfold measurement at seven different locations. Results of the findings showed that overall, the basketball players had higher percentages of body fat than netball players. The average percentages of body fat of basketball and netball players were $19.68 \pm 4.93 \%$ and $18.93 \pm 4.41 \%$, respectively. Both Malaysian national basketball and netball players' average percentage of body fat were found to be higher than the ideal average percentage of body fat range between $10-16 \%$ for female athletes in elite team sports. The players in the defence position in basketball were found to have the highest percentage of body fat $(23.00 \%)$, followed by centre position players $(21.62 \%)$ and attack position players $(15.10 \%)$. These results differed from netball players' in similar playing positions. Among the netball players, the defence position players had the highest percentage of body fat $(21.00 \%)$, followed by attack position players $(18.63 \%)$, and centre position players (16.57\%). (JUMMEC 2006; 9(1): 20-22)
\end{abstract}

KEYWORDS: Body fat, netball players, basketball players, playing position

\section{Introduction}

Basketball and netball are among the popular contact sports in Malaysia. Netball evolved from a common progenitor with basketball, and therefore, there are similarities between the games. According to a study carried out $(I, 2)$, female athletes in elite team sports such as basketball and netball need a body fat percentage of $10 \%$ to $16 \%$ or skinfold value of $70-90 \mathrm{~mm}$ (averaged from seven locations) to perform well or to achieve their full playing potential. They reported that players with body fat percentages of $12 \%$ to $16 \%$ had better overall physical fitness, better movement and tired less easily compared to players who were reported to have skinfold values exceeding the ideal level. Body fat in excess of $25 \%$ would limit the players' movements. They would also be tired faster from lugging the extra weight around. Moreover, more oxygen would be needed to catabolize the fat for the extra energy required (3). All these would lower their level of play. Hence, the purpose of this study is to compare the body fat percentage among elite basketball and netball players in Malaysia, and to identify whether the body fat value was in line with the suggestion given $(1,2)$.

\section{Methods and Procedures}

\section{Subjects}

Twenty-three physically active elite Malaysian basketball $(\mathrm{N}=12)$ and netball $(\mathrm{N}=\mathrm{II})$ players were chosen for this study. The basketball and netball players were elite players who represented Malaysia in the 1997 Southeast Asia Games in Jakarta, Indonesia and the 1998 Commonwealth Games in Kuala Lumpur, respectively. Players from both teams were elite players as they were the best national teams in Malaysia, and participated in the highest level of competition in their respective games. The subjects were divided into three categories, i.e., defender/guard, centre, and attacker/

\footnotetext{
Correspondence:

Soh Kim Lam

Department of Community Health

Faculty of Medicine and Health Sciences

University Putra Malaysia

43400 UPM Serdang

Selangor Darul Ehsan, Malaysia

Tel: 603-8946 8153 (Office) or 6019-364 9715 (Mobile)

Fax: 603-8943 5386

Email:kim@educ.upm.edu.my or kimgeoks@yahoo.com
} 
forward. The physical characteristics of the subjects for the games are shown in Table I.

\section{Procedure and Instrumentation}

The study was carried out at the Malaysian National Sports Institute, Bukit Jalil. A trained physiologist, who was working with the institute, took these measurements. According to Tothill and Stewart, measurements taken by trained personnel should be fairly reliable (4). Seven locations were pinched - chest, midaxilla, subscapular, triceps, suprailiac, navel, and thigh using a Harpenden caliper. Seven skinfold location sites were chosen because the more locations taken, the more accurate the results would be (5). Furthermore, more skinfold sites taken were also reported to have higher correlation $(r=0.85)$ with Hydrostatic Weighing $(6,7)$. The calculation of body fat content was based on the formula (6).

\section{Statistical Analysis}

The overall and based on playing positions body fat contents were reported in percentages and the body fat comparison between both teams were done directly based on the percentages (8). Besides that, both the body fat percentage values obtained were also used to determine whether they were in line with the suggestion given $(I, 2)$.

\section{Results}

A mean body fat percentage of $19.68 \pm 4.93 \%$ was reported among the elite basketball players. The body fat range in this study was $10.40 \%$ to $26.20 \%$ (Table 2). The defence women basketball players had the highest body fat percentage, followed by the centre and attack players. The body fat percentages among the basketball players based on the above playing positions were $23.00 \pm 3.39 \%$ (defence), $21.62 \pm 3.91$ (centre), and $15.10 \pm 4.12 \%$ (attack), respectively (Table 3). Meanwhile, the netball players had a mean of $18.93 \pm 4.41 \%$ body fat. The body fat range was from $13.20 \%$ to $25.70 \%$ (Table 2). Defence netball players had the highest body fat percentage of $21.00 \pm 4.89 \%$, followed by attack $18.63 \pm 5.40 \%$, and centre $16.57 \pm 5.40 \%$ position players (Table 3 ).

Table I. Mean values of physical characteristics for the basketball and netball players

\begin{tabular}{llllllll}
\hline Teams & N & \multicolumn{2}{c}{ Age (years) } & \multicolumn{2}{c}{ Height $(\mathrm{cm})$} & \multicolumn{2}{c}{ Body Mass $(\mathrm{kg})$} \\
& & Mean & SD & Mean & SD & Mean & SD \\
\hline Basketball & 12 & 22.75 & 2.67 & 171.71 & 5.45 & 63.88 & 6.46 \\
Netball & II & 23.91 & 3.36 & 168.70 & 6.74 & 61.34 & 7.92 \\
\hline
\end{tabular}

Table 2. Body fat percentages (\%) among basketball and netball players

\begin{tabular}{lccc}
\hline Basketball Players & Body Fat (\%) & Netball players & Body Fat (\%) \\
\hline 1 & 18.30 & 1 & 21.50 \\
2 & 10.40 & 2 & 20.90 \\
3 & 18.80 & 3 & 17.30 \\
4 & 12.90 & 4 & 14.80 \\
5 & 22.00 & 5 & 13.20 \\
6 & 16.60 & 6 & 13.70 \\
7 & 19.00 & 7 & 22.80 \\
8 & 26.20 & 8 & 19.50 \\
9 & 26.10 & 9 & 24.00 \\
10 & 19.80 & 10 & 25.70 \\
11 & 25.40 & 11 & 14.80 \\
12 & 20.60 & & $13.20-25.70 \%$ \\
\hline Body Fat Range & $10.40-26.20 \%$ & & $18.93 \pm 4.41$ \\
\hline Mean and SD & $19.68 \pm 4.93$ & & \\
\hline
\end{tabular}


Table 3. Mean body fat percentage (\%) based on playing position

\begin{tabular}{lcccccccc}
\hline Teams & & \multicolumn{4}{c}{ Positions } & \multicolumn{2}{c}{ Overall } \\
& Attack & SD & Centre & SD & Defense & SD & Mean & SD \\
\hline Basketball & 15.10 & 4.12 & 21.62 & 3.91 & 23.00 & 3.39 & 19.68 & 4.93 \\
Netball & 18.63 & 3.15 & 16.57 & 5.40 & 21.00 & 4.89 & 18.93 & 4.41 \\
\hline
\end{tabular}

\section{Discussion}

The overall body fat percentages of $19.86 \%$ and $18.93 \%$ among the Malaysian basketball and netball players were found to be higher compared to the ideal norm of $10 \%$ to $16 \%$ (I). However, there were two basketball players and four netball players who had body fat percentages within the $10 \%$ to $16 \%$ range. The range of percentage of body fat among the Malaysian basketball and netball players is between $10.40 \%$ to $26.20 \%$ and $13.20 \%$ to $25.70 \%$, respectively (Table 2 ). Results of this study also showed that there were three basketball players and one netball player with body fat percentages exceeding $25 \%$. According to research (I), body fat in excess of $25 \%$ would limit the players' movements. They would also become tired faster from lugging the extra weight around. Moreover, more oxygen would be needed to catabolize the fat for the extra energy required (3). All these would lower their level of playing performance and prevent them from playing to their full potential (2). Meanwhile, for playing position, only attack basketball players were found to have the most suitable body fat percentage for a good basketball player. These players had mean body fat percentage of $15.10 \%$ (Table 3 ).

\section{Conclusion}

The Malaysian elite women basketball and netball players were found to have higher body fat percentages compared to the elite basketball players' norm of $10 \%$ to $16 \%(1)$. Of all the subjects, only two basketball players and four netball players were found to have suitable body fat percentages required to be a good basketball or netball player. Most of the basketball and netball players were found to have acceptable body fat percentage, i.e., body fat less than $25 \%$. However, three basketball players and one netball player had body fat percentages exceeding the $25 \%$ (Table 2), which is considered high for elite national players (9). An above average body fat was reported to have an impact on running speed, jumping ability and endurance performance (2).

\section{Acknowledgement}

The authors wish to thank the Malaysian Basketball Association (MABA) and Malaysian Netball Association (MNA) for the support in this study. Gratitude is also expressed to the basketball and netball coaches, Mr. Tan SW and Miss Choo KL, and the subjects who participated in this study. A special thank you also to Malaysian National Sports Institute staff who had given their technical and material support.

\section{References}

I. Wilmore JH, Costill DL. Physiology of sports and exercise. Champaign: Human Kinetics Publisher, 1994.

2. Telford R, Barnes J, Tumilty D, et al. Body fat measures in athletes with a special reference to female basketballers and netballers. Sports Coach 1985; 9(I): 32-37.

3. Fox EL, Bowers RW, Foss ML. The physiological basis of athletics (4th ed.). Dubuque: Wm. C. Brown Publishers, 1989.

4. Tothill P, Stewart A. Estimation of thigh muscle and adipose tissue volume using magnetic resonance imaging and anthropometry. Journal of Sport Sciences 2002; 20(7): 563-576.

5. Johnson BL, Nelson JK. Practical measurement for evaluation in physical education (4th ed.). Edina: Burgess Publishing, 1986.

6. Pollock ML, Schmidt HD, Jackson AS. Measurement of cardiorespiratory fitness and body composition in the clinical setting. Comprehensive Therapy 1980; 6(9): 12-27.

7. Adams GM. Exercise physiology: Laboratory manual (2nd ed.). Dubuque: Brown and Benchmark Publisher, 1994.

8. Pallant S. SPSS Survival Manual: A step-by-step guide to data analysis using SPSS (version 10). Illinois: Allen and Unwin, 200I.

9. Sharkey BJ. Physiology of fitness (3rd ed.). Illinois: Human Kinetics Books, 1990. 